\title{
ANOMALOUS PULMONARY VEIN DRAINAGE INTO THE CORONARY SINUS
}

BY

\author{
M. W. ARTHURTON, R. V. GIBSON, AND G. M. WOODWARK
}

From the Padiatric and Cardiographic Departments, Westminster Hospital

Brody (1942) in his review of the literature found six examples of total anomalous pulmonary vein drainage into the coronary sinus (Nabarro, 1902; De Groat and Thatcher, 1936; Nagel, 1936; Palmer, 1938; and Terplan and Sanes, 1938), and described a further one of his own. A detailed account of a similar case with autopsy findings is given by Taussig (1947), in which the clinical diagnosis of atrial septal defect had been made. A further example is reported by Snellen and Albers (1952), but no details are given.

The case presented below is believed to be one of total anomalous pulmonary vein drainage into the coronary sinus. As far as the authors are aware, the diagnosis of this anomaly during life has not yet been reported.

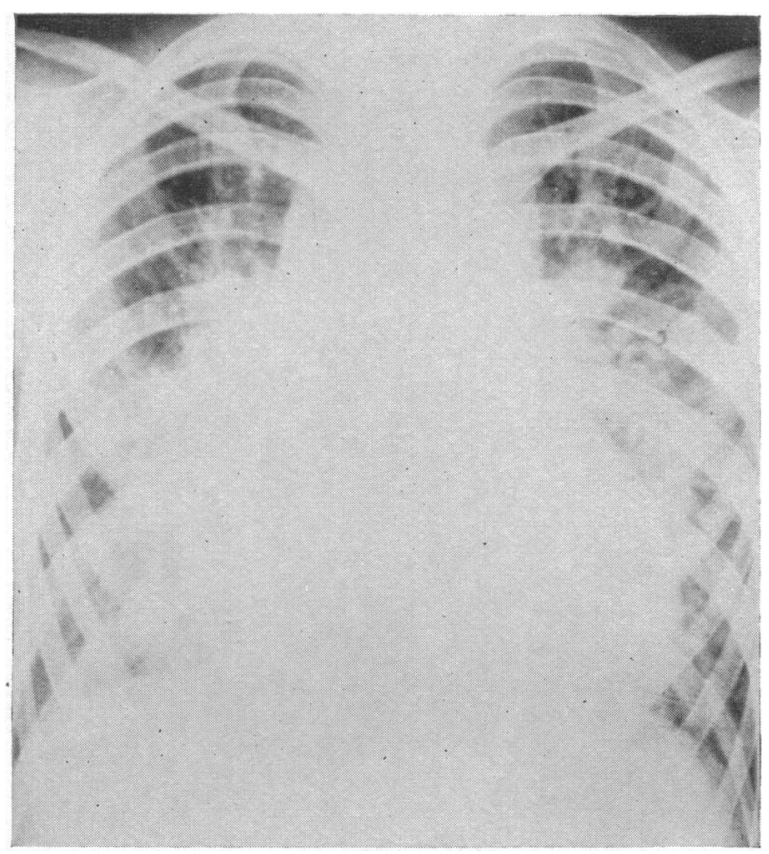

FIG. 1.-Skiagram showing left superior vena cava, enlargement of right heart, and gross pulmonary plethora. 


\section{Case Report}

A girl, aged 5 years, was referred on account of a heart murmur, with dyspnœa and fatigue on effort. There was no past history of respiratory infections.

She was under-developed; there was no central cyanosis nor clubbing of the fingers and toes. The jugular venous pressure was $3 \mathrm{~cm}$. above the sternal angle at $60^{\circ}$. The radial pulse was of small volume, and the blood pressure $90 / 70$. Clinically there was moderate cardiac enlargement confirmed by the skiagram showing enlargement of the heart to the right and left with markedly pleonæmic lungs (Fig. 1). Systolic pulsation was present in the second to fourth intercostal spaces to the left of the sternum. The second heart sound was widely split and the pulmonary element was not accentuated. There was a loud, high-pitched systolic murmur heard over the pulmonary area and a low-pitched mid-diastolic murmur at the apex. The cardiogram showed partial right bundle branch block, and in lead V1 the duration of QRS was $0 \cdot 1 \mathrm{sec}$. and $R^{\prime}$ measured $14 \mathrm{~mm}$.

On cardiac catheterization the catheter passed readily from the right atrium to the left superior vena cava

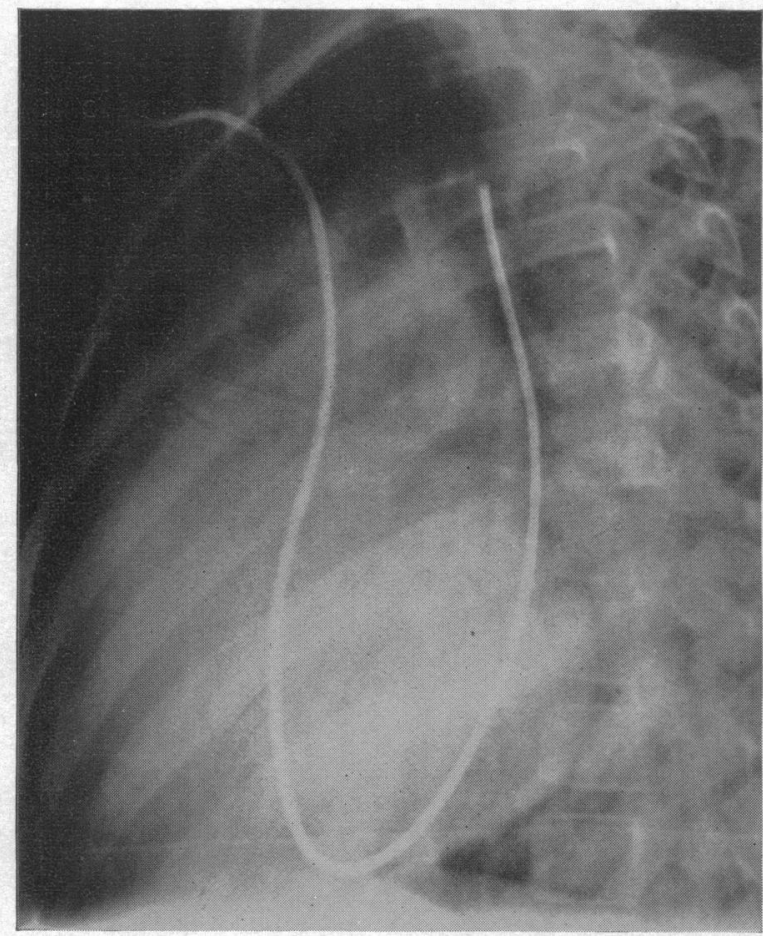

Fig. 2.-Skiagram in left oblique view showing catheter passing from right atrium to left superior vena cava along the normal course of the coronary sinus.

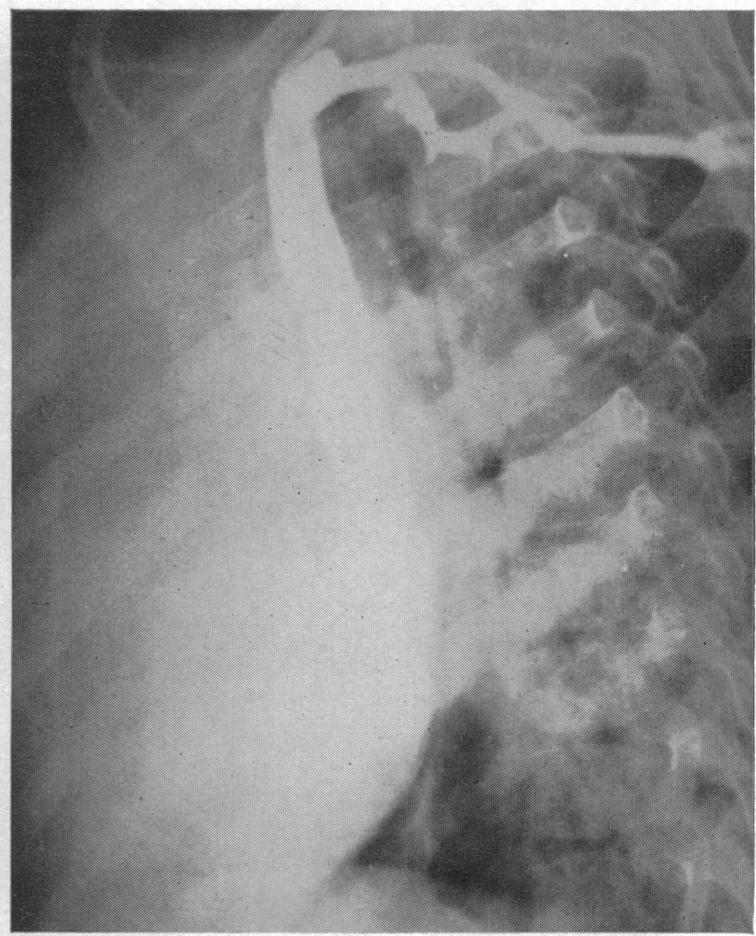

FIG. 3.-Angiogram in left oblique at $1 \cdot 2$ sec. showing left superior vena cava draining into aneurysmal coronary sinus.

following the normal course of the coronary sinus (Fig. 2). Samples were taken in rapid sequence and their oxygen content was estimated by Van Slyke's method, and as will be seen in the table, the oxygen content of the right atrial sample is much higher than those from the venæ cavæ, but the striking feature is that the oxygen content of samples from the femoral artery, pulmonary artery, and right ventricle are identical, within the limits of experimental error, confirming that the pulmonary and systemic circulations are supplied from a common source, the right atrium.

The variation of the right atrial samples was thought to be due to stream-line effects.

On venous angiocardiography, in the left oblique view and using the left arm, the left superior vena was shown at $1.2 \mathrm{sec}$. opening into a large spherical chamber situated postero-inferiorly where the dye is immediately diluted (Fig. 3). Subsequent films show simultaneous filling of both sides of the heart. 
Table Showing Results of Cardiac Catheterization

\begin{tabular}{|c|c|c|c|c|c|}
\hline & $\begin{array}{l}\text { Superior } \\
\text { vena cava }\end{array}$ & $\begin{array}{l}\text { Right } \\
\text { atrium }\end{array}$ & $\begin{array}{c}\text { Right } \\
\text { ventricle }\end{array}$ & $\begin{array}{l}\text { Pulmonary } \\
\text { artery }\end{array}$ & $\begin{array}{l}\text { Femoral } \\
\text { artery }\end{array}$ \\
\hline Oxygen content, ml./litre & $\begin{array}{l}124(\mathrm{R}) \\
125(\mathrm{~L})\end{array}$ & $\begin{array}{l}145 \text { (low) } \\
166 \text { (mid) } \\
156 \text { (high) }\end{array}$ & 152 & 149 & 147 \\
\hline $\begin{array}{l}\text { Percentage oxygen saturation } \\
\text { Pressure, } \mathrm{mm} . \mathrm{Hg}\end{array}$ & 66 & $83^{-}$ & $\begin{array}{r}81 \\
20 / 1\end{array}$ & $\begin{array}{r}80 \\
20 / 7\end{array}$ & $\begin{array}{c}79 \\
60 / 30\end{array}$ \\
\hline
\end{tabular}

Oxygen capacity $=187 \mathrm{ml} . /$ litre.

After inhalation of pure oxygen for 5 minutes, the arterial oxygen saturation was 90 per cent.

\section{Discussion}

The electrocardiogram and chest X-ray conform with the clinical diagnosis of atrial septal defect. However, the oxygen saturation of the blood in the right heart and in the femoral artery were identical. This does not occur in uncomplicated atrial septal defect, but is diagnostic of total anomalous pulmonary vein drainage into the right atrium or its tributaries. A right-to-left shunt is shown by the arterial desaturation, which did not rise above 90 per cent on breathing oxygen, excluding desaturation due to increased pulmonary blood flow.

Angiocardiography demonstrated an aneurysmal coronary sinus at the site of the anomalous pulmonary vein drainage. The course of the circulation was as follows: the right atrium receives all the systemic and pulmonary venous blood, the larger proportion of which passes to the right ventricle and thence to the lungs, and the smaller proportion to left atrium via an atrial septal defect or patent foramen ovale and thus to the systemic circulation. The development of surgical closure of atrial septal defects renders it imperative that anomalous pulmonary vein drainage be distinguished from atrial septal defect. In the former, anastomosis of pulmonary veins to the left atrium will be required prior to closure of the atrial septal defect.

\section{Summary}

A case of total anomalous pulmonary vein drainage into the coronary sinus is described, in which the diagnosis has been made during life. The differential diagnosis from atrial septal defect is discussed.

We wish to thank Dr. Ian Anderson for his encouragement and permission to publish this case. We are also indebted to Dr. R. Wylie Smith, who originally referred this patient; to Dr. C. J. Gavey and to Dr. Peter Kerley for placing at our disposal the facilities of the Cardiographic and Radiological Departments respectively; and to Dr. J. H. Wilkinson of the Chemical Pathology Department, who performed the gas analysis.

\section{REFERENCES}

Brody, H. (1942). Arch. Path., 33, 221.

De Groat, A. F., and Thatcher, H. S. (1936). J. tech. Meth., 16, 93.

Nabarro, D. (1902). J. Anat. Lond., 37, 382.

Nagel, A. (1936). Virchows Arch., 297, 343.

Palmer, W. H. (1938). J. tech. Meth., 18, 114.

Snellen, H. A., and Albers, F. H. (1952). Circulation, 6, 801.

Taussig, H. (1947). Congenital Malformation of the Heart. Commonwealth Fund, New York, Fig. 100.

Terplan, K., and Sanes, S. (1938). J. tech. Meth., 18, 176. 